\title{
ANALISIS RISIKO USAHATANI PADI SAWAH METODE SYSTEM OF RICE INTENSIFICATION (SRI) DAN TANAM BENIH LANGSUNG (TABELA) DI DESA TONUSU KECAMATAN PAMONA PUSELEMBA
}

\author{
Risk Analysis of Rice Field Farming between Methods of System of Rice \\ Intensification (SRI) and Direct Seed Planting (Tabela) \\ at Tonusu Village Pamona Puselemba District
}

\author{
Marianne Reynelda Mamondol ${ }^{1)}$ \\ Delcen Sopani $^{2)}$ \\ 1,2 Fakultas Pertanian Universitas Kristen Tentena \\ Jln. Torulemba No. 21 Tentena, Poso, Sulawesi Tengah \\ e-mail: mariannemamondol@ymail.com
}

\begin{abstract}
Abstrak
Penelitian ini bertujuan untuk mengetahui risiko usahatani padi sawah metode System of Rice Intensification (SRI) dan tanam benih langsung (Tabela) di Desa Tonusu Kecamatan Pamona Puselemba Kabupaten Poso. Data dikumpulkan melalui survey yang dilaksanakan dalam bentuk pengisian kuisioner dan wawancara dengan subyek penelitian. Sampel sebanyak 20 orang petani padi sawah diambil dengan menggunakan teknik sampling berstrata, masing-masing strata terdiri dari 10 petani yang menerapkan metode tanam SRI dan 10 petani yang menerapkan metode Tabela. Data dianalisis dengan menggunakan analisis pendapatan, analisis perbedaan produksi, penerimaan, biaya produksi, dan pendapatan pada kedua metode tanam, serta analisis risiko. Hasil penelitian menunjukkan bahwa untuk petani yang menerapkan metode tanam SRI diperoleh rata-rata produksi sebesar 4 ton/ha/MT, rata-rata penerimaan $R p$ 16.800.000,-/MT, rata-rata biaya produksi $R p$ 5.615.550,-/MT, dan rata-rata pendapatan Rp 11.196.450,-/MT. Pada petani yang menerapkan metode Tabela diperoleh rata-rata produksi sebesar 2,19 ton/ha/MT, rata-rata penerimaan Rp 6.200.000,-/MT, rata-rata biaya produksi Rp 2.650.150,-/MT, dan rata-rata pendapatan Rp 3.579.850,-/MT. Hasil uji $t$ 2 sampel independen menunjukkan bahwa terdapat perbedaan yang signifikan antara kedua metode penanaman dalam variabel produksi, penerimaan, biaya produksi, dan pendapatan. Koefisien variasi pendapatan petani yang menerapkan metode Tabela lebih besar dibandingkan dengan pada petani yang menerapkan metode SRI. Hasil uji t 2 sampel independen memperlihatkan bahwa terdapat perbedaan antara kedua nilai koefisien variasi, dengan demikian metode Tabela memiliki risiko yang lebih besar terhadap pendapatan petani dibandingkan dengan metode SRI.
\end{abstract}

Kata Kunci: risiko, usahatani padi sawah, metode Tabela, metode SRI

\begin{abstract}
This research aims to find out the risk for rice field farming with methods of System of Rice Intensification (SRI) and direct seed planting (Tabela) at Tonusu Village Pamona Puselemba District Poso Regency. Data is collected through survey which is conducted in filling out the questionnaires and interviewing research subjects. 20 farmers as samples are taken by using stratified sampling technique, where each category consists of 10 farmers who apply SRI and Tabela planting methods respectively. Data is analyzed using analyses of income, differences of production, revenue, cost production, and income on both planting methods, and risk. Results points out that for farmers who apply SRI method, the averages of production, revenue, cost production, and income are respectively 4 ton/ha/harvest, Rp 16,800,000/harvest, $\operatorname{Rp}$ 5,615,550/harvest, and Rp 11,196,450/harvest. Farmers who conduct Tabela method get averages production, revenue, cost production, and income consecutively 2.19 ton/ha/harvest, $R p$ 6,200,00/harvest, $R p$ 2,650,150/harvest, and $R p$ 3,579,850/harvest. According to $t$ test for 2 independent samples, there is a significant difference between the two methods on variables of production, revenue, cost production, and income. Coefficient of variation for farmers' income who apply Tabela method is higher than that of farmers who apply SRI method. The result of $t$ test for 2
\end{abstract}


independent samples indicates that there is difference between those two variation coefficient, so that it is concluded that Tabela method has higher risk on farmer's income than SRI method.

Keywords : risk, rice field farming, Tabela method, SRI method

\section{PENDAHULUAN}

Peningkatan produksi di bidang pertanian merupakan dampak dari penerapan berbagai teknik atau metode terbaru dalam usahatani. Hal ini dimaksudkan untuk menjawab kebutuhan masyarakat akan produk-produk pertanian yang semakin meningkat setiap tahunnya. Mosher dalam Hanafie (2010) menyatakan bahwa salah satu syarat mutlak yang diperlukan dalam pembangunan pertanian ialah inovasi teknologi yang senantiasa berubah lebih maju, yang dapat memberikan kenaikan hasil yang signifikan serta penurunan pada biaya produksi.

Inovasi merupakan penemuan baru yang berupaya meningkatkan kinerja suatu aktivitas. Inovasi yang dihasilkan dari ilmu pengetahuan yang bersifat teknis disebut inovasi teknis. Di bidang pertanian tanaman, contoh inovasi teknis ialah penemuan bibit atau benih varietas baru, penemuan traktor sebagai pengganti tenaga kerja manusia atau hewan, pengembangan pupuk atau obat-obatan pemberantas organisme pengganggu tanaman dari bahan-bahan organik, dan penemuan atau pengembangan metode-metode atau teknikteknik budidaya tanaman yang terbaru melalui kegiatan penelitian dan pengembangan (research and development) (Panuju et al., 2013).

Pada pertanian padi sawah, metode Tanam Benih Langsung (Tabela) merupakan metode yang dikembangkan sebagai alternatif bagi metode Tanam Pindah (Tapin) yang umum dilakukan oleh petani. Metode Tabela dikembangkan dengan tujuan untuk mengefisienkan penggunaan tenaga kerja dan memperpendek periode produksi padi sawah. Efisiensi penggunaan tenaga kerja diperoleh dari tidak dilakukannya pembuatan persemaian, pemupukan bibit, pencabutan bibit, pengangkutan bibit, dan penanaman bibit. Menurut Pane (2003), rata-rata curahan tenaga kerja untuk penanaman padi dengan metode Tabela dan Tapin ialah masing-masing 1,80 dan 25 hari kerja/ha, sedangkan curahan tenaga kerja untuk penyiangan ialah $150 \mathrm{jam}$ kerja/ha untuk metode Tabela dan $450 \mathrm{jam}$ kerja/ha untuk metode Tapin. Ini menunjukkan bahwa metode Tabela mampu menghemat curahan tenaga kerja dan menekan biaya produksi sehingga memberikan keuntungan bagi petani.

Beberapa kelemahan yang terdapat pada metode Tabela ialah kebutuhan bibit yang lebih banyak serta biaya pupuk dan pestisida anorganik yang semakin meningkat. Pada umumnya petani yang menerapkan metode Tabela menggunakan input-input kimia sintetik dalam proses produksinya. Selain itu metode Tabela lebih cocok dilakukan di musim kemarau, sebab bila dilakukan pada musim hujan maka benih akan terendam air dan membusuk (Lita et al, 2013).

Selanjutnya berkembang metode System of Rice Intensification (SRI) sebagai pendekatan dalam budidaya tanaman padi yang memberikan penekanan pengelolaan tanah, tanaman, dan air melalui pemberdayaan kelompok dan kearifan lokal dengan berlandaskan praktik-praktik budidaya yang ramah lingkungan. Ide tentang metode SRI mulai dikembangkan di Madagaskar pada awal tahun 1980 oleh Fr.Henri de Laulanie, S.J., kemudian diujicobakan di beberapa negara Asia seperti India, Bangladesh, Srilanka, Cina, Filipina, dan Vietnam. Di Indonesia, uji coba metode SRI pertama kali dilakukan oleh Lembaga Penelitian dan Pengembangan Pertanian di Sukamandi, Jawa Barat pada musim tanam 1999-2000. Pada musim kemarau diperoleh produksi padi sebesar 6,2 ton/ha, sedangkan pada musim penghujan diperoleh produksi padi sebesar 8,2 ton/ha. Hasil penelitian Anugrah et al (2008) menunjukkan bahwa di Kabupaten Garut dan Ciamis, Jawa Barat, hasil padi yang diperoleh melalui metode SRI rata-rata berkisar $5-7$ ton per hektar, sedangkan bila diusahakan secara konvensional hasil padi hanya berkisar antara $4-5$ ton per hektar.

Lebih lanjut Anugrah et al (2008) menyatakan bahwa aplikasi metode SRI didasarkan pada enam komponen penting, yaitu : 1) bibit dipindahkan ke lapangan lebih awal (bibit muda) pada umur 8 -15 hari untuk mengurangi kerusakan akar dan menghasilkan jumlah anakan lebih banyak, 2) bibit ditanam satu per satu guna mengurangi persaingan ruang tumbuh, cahaya, dan unsur hara, 3) jarak tanam lebar untuk mencapai jumlah anakan 
maksimum, 4) kondisi tanah lembab dan tidak tergenang air dengan menggunakan irigasi berselang agar kondisi perakaran tidak teroksidasi dan akar tanaman tumbuh lebih panjang dan lebat, 5) melakukan penyiangan gulma dengan menggunakan peralatan sederhana seperti gasrok atau lalandak agar areal bersih dari gulma, struktur tanah diperbaiki dan aerasi tanah ditingkatkan, dan 6) penggunaan pupuk dari bahan organik berupa kompos untuk memperbaiki struktur dan tekstur tanah. Jadi secara singkat dapat dikatakan bahwa metode SRI merupakan metode yang mengupayakan penghematan penggunaan air, biaya produksi, benih/bibit, dan waktu untuk berproduksi karena panen yang lebih awal, di samping penggunaan input pupuk dan pestisida organik. Produk padi organik yang dihasilkan memiliki keunggulan dari segi cita rasa dan keamanan dari pencemaran oleh residu kimia (Syam, 2006)..

Walaupun demikian, metode SRI juga memiliki sejumlah kelemahan, di antaranya risiko kegagalan karena menggunakan bibit muda dengan cara tanam satu per satu terutama jika curah hujan tinggi dan lahan tergenang, di mana banyak bibit yang hanyut. Selain itu, intensifnya penyiangan gulma mengakibatkan tambahan waktu pemeliharaan dan kebutuhan tenaga kerja. Persepsi sebagian petani yang masih meragukan keberhasilan metode SRI menyebabkan masih banyak petani yang belum menerapkan metode ini dalam praktik budidaya tanaman padi sawah (Glover, 2011).

Desa Tonusu di Kecamatan Pamona Puselemba merupakan salah satu lokasi penanaman padi sawah secara intensif di Kabupaten Poso. Terdapat 120 petani yang menerapkan metode Tabela dan 20 petani yang menerapkan metode SRI dalam aktivitas budidaya tanaman padi sawah. Pilihan penggunaan metode penanaman terutama diarahkan pada perolehan produksi yang lebih tinggi yang memberikan keuntungan yang maksimum bagi petani sebagai pengelola usahatani. Di samping itu, petani juga ingin memperkecil risiko yang akan dihadapi jika memilih salah satu alternatif metode, karena setiap metode penanaman memiliki konsekuensi keunggulan dan kelemahannya masing-masing. Risiko yang lebih kecil akan menghasilkan pendapatan yang lebih besar dari operasi usahatani yang dilakukan oleh petani.

Penelitian ini bertujuan untuk mengetahui risiko usahatani padi sawah metode System of Rice Intensification (SRI) dan tanam benih langsung (Tabela) pada petani di Desa Tonusu Kecamatan Pamona Puselemba Kabupaten Poso, dalam hal ini risiko terhadap pendapatan petani dari penerapan masing-masing metode tanam tersebut.

\section{METODE PENELITIAN}

Penelitian ini dilaksanakan di Desa Tonusu Kecamatan Pamona Puselemba Kabupaten Poso pada bulan September hingga November 2014. Pengumpulan data dilakukan dengan menggunakan metode survey. Survey dilakukan dengan mengadakan observasi, wawancara antara peneliti dengan subyek penelitian, dan pengisian kuisioner.

Populasi dalam penelitian ini ialah 140 petani padi sawah, terdiri dari 120 petani yang menerapkan metode Tabela dan 20 petani yang menerapkan metode SRI. Subyek penelitian ditentukan dengan teknik sampling berstrata, sehingga diperoleh 20 sampel petani yang terdiri dari 10 petani yang menerapkan metode Tabela dan 10 petani yang menerapkan metode SRI. Pemilihan sampel dalam setiap strata dilakukan secara purposif, yaitu petani yang mengusahakan areal tanam seluas $\leq 0,5$ ha.

Data yang dikumpulkan ialah data primer dengan sumber data ialah petani responden. Data primer yang dikumpulkan ialah : (a) Identitas responden, (b) Luas tanam, (c) Penerimaan petani dari produksi padi sawah, (c) Harga jual padi sawah, (d) Biaya pajak lahan, (e) Peralatan usahatani yang digunakan (jenis dan jumlah alat, tahun pembelian, harga pembelian), (f) Penggunaan pupuk dan pestisida (kebutuhan dan biaya pembelian), (g) Penggunaan tenaga kerja (asal tenaga kerja, jumlah dan biaya tenaga kerja untuk berbagai kegiatan, dan (h) Biaya pembelian sak, sewa peralatan, angkutan gabah, serta sewa huller. Penerimaan dan biaya dihitung selama 1 musim tanam (MT).

Variabel-variabel yang digunakan dalam penelitian ini ialah : (a) Penerimaan total, yaitu penerimaan petani dari penjualan beras, (Rp/MT), (b) Penerimaan petani dari penjualan beras, yaitu produksi beras per MT dikalikan dengan harga jual beras per unit (Rp/MT), (c) Produksi beras, yaitu kuantitas beras yang dihasilkan pada saat panen (ton/ha), (d) Harga jual beras, yaitu harga penjualan beras per unit dari petani kepada pedagang ( $\mathrm{Rp} / \mathrm{kg})$, (e) Biaya produksi, yaitu jumlah seluruh biaya yang dikeluarkan oleh petani untuk usahatani 
padi sawah selama satu musim tanam ( $\mathrm{Rp} /$ MT), (f) Pendapatan, yaitu selisih antara penerimaan total dengan biaya produksi (Rp / MT), (g) Luas tanam, yaitu besarnya lahan yang diusahakan oleh petani untuk budidaya tanaman padi sawah (ha), dan (h) Risiko, yaitu besarnya koefisien variasi yang diperoleh dari hasil bagi antara standar deviasi dan nilai rata-rata pendapatan usahatani padi sawah dikalikan 100 $\%$.

Teknik analisis data yang digunakan dalam penelitian ini ialah :

1) Analisis pendapatan dengan rumus :

$\pi=\mathrm{TR}-\mathrm{TC}$

(Rahardja dan Manurung, 2006)

di mana :

$\pi=\mathrm{P} . \mathrm{Q}-\mathrm{TC}$

Keterangan :

$\pi=$ Pendapatan $(\mathrm{Rp} / \mathrm{MT})$

$\mathrm{TR}=$ Penerimaan total $(\mathrm{Rp} / \mathrm{MT})$

$\mathrm{TC}=$ Biaya produksi $(\mathrm{Rp} / \mathrm{MT})$

$\mathrm{P}=$ Harga jual beras $(\mathrm{Rp} / \mathrm{kg})$

$\mathrm{Q}=$ Produksi beras $(\mathrm{kg})$

2) Analisis perbedaan produksi, penerimaan, biaya produksi, dan pendapatan usahatani padi sawah metode Tabela dan SRI menggunakan uji t 2 sampel independen dengan rumus :

$\mathrm{t}=\frac{\overline{\mathrm{x}}_{1}-\overline{\mathrm{x}}_{2}}{\sqrt{\frac{\left(\mathrm{n}_{1}-\mathrm{n}_{2}\right) \mathrm{s}_{1}^{2}+\left(\mathrm{n}_{2}-1\right) \mathrm{s}_{2}^{2}}{\mathrm{n}_{1}+\mathrm{n}_{2}-2}\left(\frac{1}{\mathrm{n}_{1}}+\frac{1}{\mathrm{n}_{2}}\right)}}$

(Hakim, 2007)

Hipotesis yang diuji ialah :

$\mathrm{H}_{0}$ : Tidak terdapat perbedaan produksi, penerimaan, biaya produksi, dan pendapatan usahatani padi sawah metode SRI dan Tabela

$\mathrm{H}_{1}$ : Terdapat perbedaan produksi, penerimaan, biaya produksi, dan pendapatan usahatani padi sawah metode SRI dan Tabela

Patokan pengambilan kesimpulan ialah : Apabila thitung $>$ t tabel pada $\alpha=5 \%$ maka $\mathrm{H}_{0}$ ditolak dan $\mathrm{H}_{1}$ diterima.

3) Analisis risiko usahatani dengan rumus :

$\mathrm{CV}=\frac{\sigma}{\overline{\mathrm{x}}} \times 100 \%$

(Somantri dan Muhidin, 2006)

Keterangan :

$\mathrm{CV}=$ Koefisien variasi

$\sigma=$ Standar deviasi pendapatan $\overline{\mathrm{x}}=$ Rata-rata pendapatan

Standar deviasi $(\sigma)$ diperoleh dengan menggunakan rumus :

$\sigma=\sqrt{\frac{\sum\left(\mathrm{x}_{\mathrm{i}}-\overline{\mathrm{x}}\right)^{2}}{(\mathrm{n}-1)}}$

(Sugiyono, 2009)

Keterangan :

$\mathrm{x}_{\mathrm{i}}=$ Pendapatan dari setiap sampel

$\overline{\mathrm{x}}=$ Rata-rata pendapatan

$\mathrm{n}=$ Jumlah sampel

Pengujian perbedaan risiko usahatani padi sawah metode Tabela dan SRI dilakukan dengan menggunakan uji t 2 sampel independen dengan rumus :

$\mathrm{t}=\frac{\overline{\mathrm{x}}_{1}-\overline{\mathrm{x}}_{2}}{\sqrt{\frac{\left(\mathrm{n}_{1}-\mathrm{n}_{2}\right) \mathrm{s}_{1}^{2}+\left(\mathrm{n}_{2}-1\right) \mathrm{s}_{2}^{2}}{\mathrm{n}_{1}+\mathrm{n}_{2}-2}\left(\frac{1}{\mathrm{n}_{1}}+\frac{1}{\mathrm{n}_{2}}\right)}}$

(Hakim, 2007)

Hipotesis yang diuji ialah :

$\mathrm{H}_{0}: \mathrm{CV}_{1}=\mathrm{CV}_{2}$

Tidak terdapat perbedaan risiko

usahatani padi sawah metode

Tabela dan SRI di Desa Tonusu

$\mathrm{H}_{1}: \mathrm{CV}_{1} \neq \mathrm{CV}_{2}$

Terdapat perbedaan risiko

usahatani padi sawah metode

Tabela dan SRI di Desa Tonusu

Patokan pengambilan kesimpulan ialah :

Apabila thitung $>$ t tabel pada $\alpha=5 \%$ maka

$\mathrm{H}_{0}$ ditolak dan $\mathrm{H}_{1}$ diterima.

\section{HASIL DAN PEMBAHASAN}

\section{1) Analisis Pendapatan}

\section{Metode SRI}

Produksi padi sawah pada petani yang menerapkan metode SRI ditunjukkan pada Tabel 1. Berdasarkan tabel dapat diketahui bahwa produksi rata-rata padi sawah pada petani dengan metode SRI ialah sebesar 4 ton/ha. Penerimaan, biaya produksi, dan pendapatan usahatani padi sawah dengan metode SRI ditunjukkan pada Tabel 2. Berdasarkan tabel diketahui bahwa rata-rata penerimaan sebesar Rp 16.800.000,-/MT, ratarata biaya produksi sebesar Rp 5.615.550,-/MT, dan rata-rata pendapatan sebesar $\mathrm{Rp}$ 11.196.450,-/MT. 
Tabel 1. Produksi Padi Sawah pada Petani dengan Metode SRI

\begin{tabular}{ccccc}
\hline No. & Responden & $\begin{array}{c}\text { Luas Tanam } \\
(\text { are })\end{array}$ & $\begin{array}{c}\text { Produksi } \\
(\mathrm{kg})\end{array}$ & $\begin{array}{c}\text { Produksi } \\
\text { (ton/ha) }\end{array}$ \\
\hline 1. & A & 0,50 & 2000 & 4,00 \\
2. & B & 0,50 & 2000 & 4,00 \\
3. & C & 0,40 & 1600 & 4,00 \\
4. & D & 0,40 & 1600 & 4,00 \\
5. & E & 0,40 & 1600 & 4,00 \\
6. & F & 0,30 & 1200 & 4,00 \\
7. & G & 0,30 & 1200 & 4,00 \\
8. & H & 0,30 & 1200 & 4,00 \\
9. & I & 0,20 & 800 & 4,00 \\
10. & J & 0,20 & 800 & 4,00 \\
\hline
\end{tabular}

Tabel 2. Penerimaan, Biaya Produksi, dan Pendapatan Usahatani Padi Sawah Metode SRI

\begin{tabular}{crrr}
\hline Responden & $\begin{array}{c}\text { Peneriman } \\
(\text { Rp/MT })\end{array}$ & $\begin{array}{c}\text { Biaya Produksi } \\
(\mathrm{Rp} / \mathrm{MT})\end{array}$ & $\begin{array}{c}\text { Pendapatan } \\
(\mathrm{Rp} / \mathrm{MT})\end{array}$ \\
\hline A & 24.000 .000 & 7.890 .000 & 16.110 .000 \\
B & 24.000 .000 & 7.845 .500 & 16.154 .500 \\
C & 19.200 .000 & 6.759 .350 & 12.440 .650 \\
D & 19.200 .000 & 6.591 .350 & 12.608 .650 \\
E & 19.200 .000 & 6.680 .600 & 12.519 .400 \\
F & 14.400 .000 & 4.506 .950 & 9.933 .050 \\
G & 14.400 .000 & 4.745 .200 & 9.694 .800 \\
H & 14.400 .000 & 4.773 .450 & 9.666 .550 \\
I & 9.600 .000 & 3.181 .550 & 6.418 .450 \\
J & 9.600 .000 & 3.181 .550 & 6.418 .450 \\
\hline Rerata & 16.800 .000 & 5.615 .550 & 11.196 .450 \\
\hline
\end{tabular}

\section{Metode Tabela}

Produksi padi sawah pada petani yang menerapkan metode Tabela ditunjukkan pada Tabel 3. Berdasarkan tabel dapat diketahui bahwa produksi rata-rata padi sawah pada petani dengan metode Tabela ialah sebesar 2,19 ton/ha. Penerimaan, biaya produksi, dan pendapatan usahatani padi sawah dengan metode Tabela ditunjukkan pada Tabel 4. Berdasarkan tabel diketahui bahwa rata-rata penerimaan sebesar Rp 6.200.000,-/MT, ratarata biaya produksi sebesar $\mathrm{Rp} 2.620 .150,-/ \mathrm{MT}$, dan rata-rata pendapatan sebesar $\mathrm{Rp} 3.579 .850$,/MT.

Tabel 3. Produksi Padi Sawah pada Petani dengan Metode Tabela

\begin{tabular}{ccccc}
\hline No. & Responden & $\begin{array}{c}\text { Luas Tanam } \\
(\text { are })\end{array}$ & $\begin{array}{c}\text { Produksi } \\
(\mathrm{kg})\end{array}$ & $\begin{array}{c}\text { Produksi } \\
\text { (ton/ha) }\end{array}$ \\
\hline 1. & A & 0,50 & 1150 & 2,30 \\
2. & $\mathrm{~B}$ & 0,50 & 1150 & 2,30 \\
3. & $\mathrm{C}$ & 0,40 & 900 & 2,25 \\
4. & $\mathrm{D}$ & 0,40 & 900 & 2,25 \\
5. & $\mathrm{E}$ & 0,40 & 900 & 2,25 \\
6. & $\mathrm{~F}$ & 0,30 & 650 & 2,17 \\
7. & $\mathrm{G}$ & 0,30 & 650 & 2,17 \\
8. & $\mathrm{H}$ & 0,30 & 650 & 2,17 \\
9. & $\mathrm{I}$ & 0,20 & 400 & 2,00 \\
10. & $\mathrm{~J}$ & 0,20 & 400 & 2,00 \\
\hline
\end{tabular}


Tabel 4. Penerimaan, Biaya Produksi, dan Pendapatan Usahatani Padi Sawah Metode Tabela

\begin{tabular}{cccc}
\hline Responden & $\begin{array}{c}\text { Penerimaan } \\
(\text { Rp/MT) }\end{array}$ & $\begin{array}{c}\text { Biaya Produksi } \\
\text { (Rp/MT) }\end{array}$ & $\begin{array}{c}\text { Pendapatan } \\
\text { (Rp/MT) }\end{array}$ \\
\hline A & 9.200 .000 & 4.152 .750 & 5.047 .250 \\
B & 9.200 .000 & 4.049 .000 & 5.151 .000 \\
C & 7.200 .000 & 3.405 .250 & 3.794 .750 \\
D & 7.200 .000 & 2.895 .000 & 4.305 .000 \\
E & 7.200 .000 & 2.325 .750 & 4.874 .250 \\
F & 5.200 .000 & 2.444 .750 & 2.755 .250 \\
G & 5.200 .000 & 2.318 .750 & 2.881 .250 \\
H & 5.200 .000 & 1.590 .750 & 3.609 .250 \\
I & 3.200 .000 & 1.590 .750 & 1.609 .250 \\
J & 3.200 .000 & 1.428 .750 & 1.771 .250 \\
\hline Rerata & 6.200 .000 & 2.620 .150 & 3.579 .850 \\
\hline
\end{tabular}

2) Analisis Perbedaan Produksi,

Penerimaan, Biaya Produksi, dan

Pendapatan Usahatani Padi Sawah

Metode SRI dan Tabela

Hasil uji t 2 sampel independen untuk menganalisis perbedaan produksi, penerimaan, biaya produksi, dan pendapatan usahatani padi sawah metode SRI dan Tabela ditunjukkan pada
Tabel 5 sebagai berikut. Hasil uji t pada Tabel 5 memperlihatkan bahwa untuk semua variabel pengamatan, nilai $t$ hitung lebih besar dibandingkan dengan $\mathrm{t}$ tabel pada $\mathrm{dk}=18$ dan $\alpha$ $=5 \%$. Dengan demikian terdapat perbedaan produksi, penerimaan, biaya produksi, dan pendapatan usahatani padi sawah pada metode SRI dan Tabela.

Tabel 5. Hasil Uji t 2 Sampel Independen

\begin{tabular}{|c|c|c|}
\hline Komponen & SRI & Tabela \\
\hline \multirow[t]{2}{*}{ Produksi rata-rata } & 4,00 ton/ha/MT & 2,19 ton/ha/MT \\
\hline & $\begin{array}{l}\mathrm{t} \text { hitung }=54,85 \\
\mathrm{t} \text { tabel }=1,734\end{array}$ & \\
\hline Penerimaan rata-rata & Rp 16.800.000/MT & $\mathrm{Rp} 6.200 .000 / \mathrm{MT}$ \\
\hline & $\begin{array}{l}\mathrm{t} \text { hitung }=16,36 \\
\mathrm{t} \text { tabel }=1,734\end{array}$ & \\
\hline Biaya produksi rata-rata & Rp 5.615.550/MT & $\mathrm{Rp} 2.620 .150 / \mathrm{MT}$ \\
\hline & $\begin{array}{l}\mathrm{t} \text { hitung }=10,08 \\
\mathrm{t} \text { tabel }=1,734\end{array}$ & \\
\hline Pendapatan rata-rata & Rp 11.196.450/MT & $\mathrm{Rp} 3.579 .850 / \mathrm{MT}$ \\
\hline & $\begin{array}{l}\mathrm{t} \text { hitung }=19,54 \\
\mathrm{t} \text { tabel }=1,734\end{array}$ & \\
\hline
\end{tabular}

Hasil uji t pada Tabel 5 memperlihatkan bahwa untuk semua variabel pengamatan, nilai t hitung lebih besar dibandingkan dengan $t$ tabel pada $\mathrm{dk}=18$ dan $\alpha=5 \%$. Dengan demikian terdapat perbedaan produksi, penerimaan, biaya produksi, dan pendapatan usahatani padi sawah pada metode SRI dan Tabela.

Peningkatan produksi padi pada metode SRI terutama disebabkan oleh jumlah anakan padi yang lebih banyak dibandingkan pada metode Tabela. Pembentukan jumlah anakan yang lebih banyak berhubungan dengan jarak tanam yang lebar pada metode SRI, yaitu $27 \mathrm{~cm}$ x $27 \mathrm{~cm}$ sehingga menyebabkan berkurangnya kompetisi antar tanaman dalam memperebutkan faktor-faktor tumbuh seperti sinar matahari, unsur hara, dan ruang tumbuh (Purnomo et al, 2011). Jumlah anakan yang lebih banyak menyebabkan pembentukan anakan produktif yang lebih besar pula sehingga hasil gabah yang diperoleh juga lebih besar. Di samping itu, penggunaan pupuk dan pestisida organik juga mampu memperbaiki kesehatan tanah dan tanaman. Padi yang dihasilkan melalui praktik budidaya tanaman secara organik juga lebih aman untuk dikonsumsi sehingga berdampak pada kehidupan yang lebih sehat.

Penerimaan usahatani padi sawah metode SRI lebih besar dibandingkan metode Tabela. Selain karena produksi yang lebih banyak, beras 
organik yang dihasilkan melalui metode SRI juga memiliki harga jual yang lebih tinggi dibandingkan harga beras pada metode Tabela. Harga beras organik pada saat penelitian dilaksanakan ialah $\mathrm{Rp} 12.000,-/ \mathrm{kg}$, sedangkan harga beras non organik ialah Rp $8.000,-/ \mathrm{kg}$. Beras organik hasil budidaya dengan metode SRI memiliki segmen pasar tersendiri dengan harga yang lebih baik. Hal ini menunjukkan adanya penghargaan konsumen terhadap produk-produk organik melalui pemberian insentif harga pasar yang lebih tinggi dibandingkan pada produk-produk non organik.

Meskipun demikian, biaya produksi pada metode SRI berbeda cukup signifikan dibandingkan metode Tabela. Metode SRI memang mampu menghemat penggunaan input berupa benih, pupuk, dan pestisida. Namun metode SRI lebih boros dalam penggunaan kompos. Kurangnya ketersediaan pupuk kandang menjadi salah satu hambatan pengembangan SRI, dikarenakan petani umumnya tidak mampu memproduksi kompos dalam jumlah yang banyak. Metode SRI juga menyebabkan penambahan tenaga kerja, terutama pada kegiatan-kegiatan berupa pembuatan kompos, pengendalian gulma, pengairan, dan pengendalian hama dan penyakit tanaman. Karena pengendalian gulma dilakukan melalui penyiangan secara manual maka kebutuhan tenaga kerja dapat meningkat sebanyak $10-30 \%$. Hal ini juga merupakan konsekuensi dari pola irigasi berselang yang memacu pertumbuhan populasi gulma yang lebih besar. Metode SRI membutuhkan pengamatan yang lebih intensif terhadap kemungkinan serangan hama dan penyakit tanaman, sehingga berdampak pada biaya tunai yang dikeluarkan untuk pembayaran tenaga kerja.

Secara keseluruhan, pendapatan usahatani padi sawah metode SRI lebih tinggi dibandingkan pada metode Tabela. Dengan demikian secara ekonomis metode SRI memberikan keuntungan yang lebih besar bagi petani sebagai pelaku usaha. Walaupun di sisi biaya terdapat pengeluaran yang cukup besar untuk pengadaan pupuk kandang dan tenaga kerja (Takahashi dan Barrett, 2013), tetapi di sisi penerimaan terdapat peningkatan produksi dan harga produk yang lebih menguntungkan.

\section{3) Analisis Risiko}

Menurut Lamusa (2010) terdapat beberapa cara untuk mengukur tingkat risiko atau ketidakpastian, di antaranya dengan menghitung koefisien variasi dari variabelvariabel yang diamati. Pada penelitian ini dilakukan perhitungan koefisien variasi dari pendapatan usahatani padi sawah metode SRI dan metode Tabela. Hasilnya dapat dilihat pada Tabel 6 sebagai berikut. Untuk menguji adanya perbedaan tingkat risiko antara kedua metode tanam maka dilakukan uji t 2 sampel independen, dengan hasil yang diperoleh ialah sebagai berikut. Nilai t hitung ialah sebesar 2,83 sedangkan nilai $\mathrm{t}$ tabel pada $\mathrm{dk}=18$ dan $\alpha=5$ $\%$. Karena t hitung lebih besar daripada t tabel maka $\mathrm{H}_{0}$ ditolak dan $\mathrm{H}_{1}$ diterima. Jadi terdapat perbedaan risiko antara pendapatan usahatani padi sawah metode SRI dan Tabela.

Tabel 6. Nilai Koefisien Variasi Pendapatan Usahatani Padi Sawah Metode SRI dan Tabela

\begin{tabular}{ccc}
\hline Jenis Usahatani & \multicolumn{2}{c}{ Kofisien Variasi } \\
\cline { 2 - 3 } & Metode SRI & Metode Tabela \\
\hline \multirow{2}{*}{ Padi Sawah } & 27,71 & 32,83 \\
\hline
\end{tabular}

Tabel 7. Nilai Uji t 2 Sampel Independen Pendapatan Usahatani Padi Sawah Metode SRI dan Tabela

\begin{tabular}{lcc}
\hline \multicolumn{1}{c}{ Metode Tanam } & thitung & $t$ tabel \\
\hline SRI & 2,83 & 1,734 \\
Tabela & & \\
\hline
\end{tabular}

Koefisien variasi pendapatan usahatani padi sawah metode Tabela lebih besar dibandingkan pada metode SRI, artinya ialah tingkat risiko atau ketidakpastian pada metode Tabela lebih besar daripada metode SRI. Praktik menanam benih secara langsung pada lokasi persawahan memiliki risiko kegagalan khususnya pada saat penanaman di musim penghujan. Debit air yang 
berlebihan dapat menghanyutkan benih sehingga benih akan gagal untuk tumbuh dan berproduksi. Akibatnya seringkali petani harus melakukan penanaman ulang, dengan risiko kebutuhan bibit bertambah banyak.

Penggunaan input usahatani juga berpengaruh terhadap risiko pendapatan yang dihadapi oleh petani. Input-input yang sifatnya mengurangi risiko (risk reducing) di antaranya ialah input pupuk, pestisida, penggunaan tenaga kerja, dan sarana irigasi. Koefisien variasi yang lebih kecil pada budidaya padi dengan metode SRI menunjukkan bahwa penggunaan pupuk dan pestisida organik memiliki kemampuan mengurangi risiko dibandingkan penggunaan pupuk dan pestisida anorganik (Prihtanti, 2014).

Rendahnya risiko pada usahatani dengan metode SRI juga disebabkan karena kesuburan tanah yang terpelihara serta keseimbangan ekosistem sawah yang mampu menekan serangan hama dan penyakit tanaman. Risiko ekologi akibat penggunaan pupuk organik dapat dikurangi, sehingga dapat memelihara kesehatan tanah dan mikroba tanah yang beraneka ragam sehingga produksi padi dapat ditingkatkan (Fitriadi dan Nurmalina, 2008).

\section{KESIMPULAN}

Terdapat perbedaan produksi, penerimaan, biaya produksi, dan pendapatan usahatani padi sawah metode SRI dan Tabela pada petani di Desa Tonusu Kecamatan Pamona Puselemba. Terdapat perbedaan koefisien variasi pendapatan petani yang menerapkan metode SRI dan Tabela. Koefisien variasi yang lebih tinggi pada metode Tabela mengindikasikan risiko yang lebih besar terhadap pendapatan petani dibandingkan pada metode SRI.

\section{REFERENSI}

Anugrah, I.S., Sumedi, dan I.P. Wardana, 2008. Gagasan dan Implementasi System of Rice Intensification (SRI) dalam Kegiatan Budidaya Padi Ekologis (BPE). Jurnal Analisis Kebijakan Pertanian. 1 (1) : 75 99.

Fitriadi, F. dan R. Nurmalina, 2008. Analisis Pendapatan dan Pemasaran Padi Organik Metode System of Rice Intensification (SRI) : Kasus di Desa Sukagalih, Kecamatan Sukaratu, Kabupaten Tasikmalaya. Jurnal
Pengkajian dan Pengembangan Teknologi Pertanian. 11 (1) : $94-103$.

Glover, D., 2011. The System of Rice Intensification : Time for an Empirical Turn. NJAS Wageningen Journal of Life Sciences. 57 (2011) : $217-224$.

Hakim, A., 2007. Statistik Induktif untuk Ekonomi dan Bisnis. Penerbit Ekonisia. Yogyakarta.

Hanafie, R., 2010. Pengantar Ekonomi Pertanian. Penerbit Andi. Yogyakarta.

Lamusa, A., 2010. Risiko Usahatani Padi Sawah Rumah Tangga di Daerah Impenso Provinsi Sulawesi Tengah. Jurnal Agroland. 17 (1) : 226 - 232.

Lita, T.N., S.Soekartomo, dan B.Guritno, 2013. Pengaruh Perbedaan Sistem Tanam Terhadap Pertumbuhan dan Hasil Tanaman Padi (Oryza sativa L.) di Lahan Sawah. Jurnal Produksi Tanaman. 1 (4) : 361 - 368.

Pane, H., 2003. Kendala dan Peluang Pengembangan Teknologi Padi Tanam Benih Langsung. Jurnal Litbang Pertanian. 22 (4) : 172 - 178.

Panuju, D.R., K.Mizuno, dan B.H. Trisasongko, 2013. The Dynamics of Rice Production in Indonesia 1961 - 2009. Journal of the Saudi Society of Agricultural Sciences. 12 (2013) : $27-37$.

Prihtanti, T.M., 2014. Analisis Risiko Berbagai Luas Pengusahaan Lahan pada Usahatani Padi Organik dan Konvensional. Jurnal Agric. 26 (1) : $29-36$.

Purnomo, D., A.Yunus, dan S.Budiastuti, 2011. Budidaya Padi Berwawasan Lingkungan dengan Metode System of Rice Intensification (SRI) dan Penggunaan Pupuk Organik Cair. Jurnal Ekosains. $\quad 8$ (1) : $25-32$.

Rahardja, P. dan M.Manurung, 2006. Teori Ekonomi Mikro : Suatu Pengantar. Lembaga Penerbit Fakultas Ekonomi UI. Jakarta. 
Somantri, A. dan S.A. Muhidin, 2006. Aplikasi Statistika dalam Penelitian. Pustaka Setia. Bandung.

Sugiyono, 2009. Statistika Untuk Penelitian. Penerbit Alfabeta. Bandung.

Syam, M., 2006. Kontroversi System of Rice Intensification (SRI) di Indonesia. Jurnal Iptek Tanaman Pangan. $1: 30-40$.

Takahashi, K. dan C.B. Barrett, 2013. The System of Rice Intensification and Its Impacts on Household Income and Child Schooling : Evidence from Rural Indonesia. American Journal of Agricultural Economics. 96 (1) : $269-298$. 
Jurnal ENVIRA Volume 2 Nomor 1 Juni 2017 